\title{
A Contrastive Study of English-Arabic Noun Morphology
}

\author{
Jamal Azmi Salim ${ }^{1}$ \\ ${ }^{1}$ Faculty of Arts, Zarqa University, Jordan \\ Correspondence: Jamal Azmi Salim, Assistant Professor of Linguistics, Faculty of Arts, Zarqa University, Jordan. \\ E-mail: jamalazmi1964@yahoo.com
}

\author{
Received: February 26, 2013 Accepted: March 28, 2013 Online Published: May 17, 2013 \\ doi:10.5539/ijel.v3n3p122 \\ URL: http://dx.doi.org/10.5539/ijel.v3n3p122
}

\begin{abstract}
The present study aims at comparing and contrasting English and Arabic noun morphology to determine the points where they differ. These differences are the main cause of difficulty in the learning of the second language. Teaching will be directed at those points where there are structural differences. This in turn determines what the teacher has to teach and what the learner has to learn. The whole focus of the present analysis will be confined to noun morphology in both languages.
\end{abstract}

Keywords: contrastive analysis, noun morphology, Modern Standard Arabic

\section{Introduction}

\subsection{Contrastive Analysis and Foreign Language Teaching}

The concept of contrastive analysis was first introduced by Charles Fries in (1952), and fully described by Robert Lado in his book Linguistics across Cultures (1957).

Contrastive analysis is a systematic branch of applied linguistics which deals with the linguistic description of the structure of two or more different languages. Such descriptive comparison serves to show how languages differ in their sound system, grammatical structure and vocabulary. This type of analysis can be used in language teaching among others, to point out the areas where the similarities and contrast between the two languages are present.

In contrastive analysis, we study the structures of two languages from two different families (i.e., the source language and the target language) in order to determine the points where they differ. These differences are the chief source of difficulty in learning a second language.

Lado states that "we assume that the student who comes in contact with a foreign language... and these elements that are different will be difficult" (1957, p. 2).

Lado was quite influenced by Charles Fries. On the first page of his book (1957), he quotes Fries, advocating the role of contrastive analysis. Fries believes that the most effective materials are those based upon a scientific description of the language to be learned, which is carefully compared with "a parallel description of the native language of the learners" (Nickel, 1971, p. 3).

Wardhaugh (1970) proposed a distinction between a strong version and a weak one of the contrastive analysis hypothesis. In its strongest formulation, the contrastive analysis hypothesis claimed that all the errors made in learning the L2 could be attributed to 'interference' by the L1. However, this claim could not be sustained by empirical evidence that was accumulated in the mid- and late 1970s. It was soon pointed out that many errors predicted by contrastive analysis were inexplicably not observed in learner's language. Even more confusingly, some uniform errors were made by learners irrespective of their L2. It thus became clear that Contrastive Analysis could not predict all learners' difficulties but was certainly useful in the respective explanation of error.

As we are aware, when the child acquires hisher native language, the child develops the native language behavior. Gradually, this becomes stronger and stronger. In learning the second language, the learner is very much influenced by his native language behavior. Where the structure of the two languages is the same or quite similar, no difficulty is anticipated. Where the structure of the second language (L2) differs from (L1), we can predict some difficulty, at least, in learning as well as error in performance. The bigger the differences between the two languages the greater the difficulty will be. Learning a second language behaviour is essential to overcome these difficulties. In other words, learning a second language involves changing one's native language 
behavior to that of the speaker of the target language.

In this respect, contrastive analysis will be useful. It will help discover the differences between the two languages concerned and predict the difficulties the learners will have to overcome. Teaching will be directed at those points where there are structural differences. This, in turn, determines to a great extent what the learner has to learn and what the teacher has to teach.

\subsection{Objectives of the Research}

The present work includes both description and comparison of the structure of English and Arabic noun morphology. Such contrastive analysis will find out the similarities and differences between the two languages. In the light of such comparison, the linguistic problems of the Arabic speakers learning English may be solved. In other words, through this comparison, the teacher will be more acquainted with the structures of the two languages in question and the areas of difficulties at the morphological level.

\subsection{Scope of the Research}

In the present work, the focus of the analysis is confined to noun morphology in both languages. The output of this paper, though, should be of practical use for teachers and learners of English and Arabic as a second language. It will also be helpful in the preparation of the textbooks to solve the problems of the learners at the level of morphology, and to solve the problem of the mother tongue interference.

\subsection{Methodology}

Arabic being the native language of the investigator, the data has been furnished by him. The data is analyzed and described through the contrastive method. Since the present work is dealing with the analysis of the noun morphology of both English and Arabic, help is also taken from various books and the alike, dealing with the modern Arabic and English language.

\subsection{Arabic Language}

"Modern standard Arabic is traditionally defined as that form of Arabic used practically in all writings of Arabic, and that form used in spoken discourse, such as news broadcasts, speeches, ceremonies and the alike" (Cowan, 1986, p. 29).

"Arabic stands among Semitic languages because of its richer sound system, an exceptional development of forms, an astounding prosperity for set patterns of word formation and word change which makes the Arabic grammar look 'algebraic', as some scholars put it, and sometimes gives an impression of artificiality" (Yushmanove, 1961, p. 4).

The major language of the Semitic group is Arabic. The characteristic feature of the Semitic languages is their basic consonantal root, mostly trilateral, variations in shades of meaning are obtained first by varying the vowel ling of the simple root and secondly by the addition of prefixes, suffixes and infixes (Haywood J. A., \& Nahmad H. M., 1965, p. 1).

\section{English Noun Morphology: Structure of English Nouns}

English nouns can be studied under the following headings:

\subsection{Stem Structure.}

2.2 Morphological processes.

\subsection{Derivation.}

2.4 Inflection.

\subsection{Stem Structure}

"A Stem is any construction to which an affix can be added. Roots always contain a single morpheme, but a stem may contain a root plus an affix. In "impossible", 'possible' is the root to which /im -/ is prefixed. In 'black-birds', 'black' and 'bird' are roots and 'blackbird' is a stem to which the suffix/-s/ is attached" (Liebert, Burt, 1971: 104).

In English, there are two basic processes of stem formation, i.e., the addition of derivational affixes to roots or stems, and the combination of two or more stems, to stem compounds.

"The following are the structural classification of stems in English" (Hocket, Charles. F. A., 1971, pp. 240-241):

I. Simple stems: consisting of a single morpheme, e.g., boy girl, woman, pen, etc.

II. Derived stems or derivatives, consisting of more than one morpheme: 
II.a. Secondary derived stems, in which only one IC itself is a stem.

II.a.1. Secondary derivatives, in which only one IC itself is a stem, the other IC is a derivational affix, e.g., 'boyish', 'manly', 'singer', 'actress', 'performance', 'befriend', etc.

II.a.2. Stem compounds, in which both (or all ICs themselves are stems, e.g., 'aircraft', 'fingerprint', 'textbook', etc.

II.b. Primary derived stems, in which no IC is itself a stem.

II.b.1. Primary derivatives, in which one IC is a derivational affix, the other is a root, e.g., 'detain', 'refer', these consist of derivational affixes /de- and re-/ and underlying roots 'detain' and 'refer'. These two affixes also occur in secondary derivatives, e.g., 'deform' and 'reform'. The roots occur only in primary derivatives.

II.b.2. Root compounds, in which neither IC is a derivational affix, e.g., 'telephone', 'telescope ','photograph', 'gramophone', etc.

\subsection{Morphological Processes}

The devices by which the constituent words of a paradigm are differentiated from one another are known as morphological processes" (Block. B and Trager. G. L., 1972, p. 56).

Five kinds of morphological processes may be distinguished.

They are as follows:

1. Affixation

2. Internal change

3. Compounding

4. Suppletion

5. Zero-modification

\subsubsection{Affixation}

Affixes are the recurrent formative morphemes of words other than roots. Affixes are of three types, which are as follows:

(i) Prefixes: Prefixed to the root, e.g., incomplete, illegal, dishonest, etc.

(ii) Suffixes: suffixed to the root, e.g., houses, boyish, darkness, etc.

(iii) Infixes: Inserted within the root, and found frequently in many languages but not in English.

\subsubsection{Internal Change}

Two or more words related in form and meaning may differ from each other in some phoneme or phonemes of the base itself. One base is then described as being derived or inflected from another in the same paradigm by internal change.

In English, the words 'sing, song' constitute a paradigm of derivation parallel to 'fly and flight, sing, sang, sung', are numbers of a paradigm of inflection, parallel to 'play, played, played'. These examples illustrate vocalic change. The noun 'house and the verb house' show consonantal change. Similar paradigm of consonantal change are 'advice and advise'.

Internal changemay also change or affect the accent of the base or the whole word, with or without vocalic and consonantal change, e.g., 'import' $(\mathrm{N})$ and 'import $(\mathrm{V})$. Internal change in the base is very common (often accompanies affixation), e.g., 'keep: kept', 'tell: told'. The study of the alternation between phonemes in the morphemes related to each other by internal change is called 'morphophonemic'.

\subsubsection{Compounding}

Two or more stems combined to form one stem is called 'compounding', e.g., blackboard, post office, blackbird, blue tooth, icebox, typewriter, etc.

\subsubsection{Suppletion}

Suppletion may be regarded as an extreme kind of internal change, in which the entire base- not merely a part of it- is replaced by another form. The English paradigm: 'go, goes, went, gone' going, shows irregularity. One of its irregularities is that the past tense of 'go' is replaced by a completely different base 'went'. In English, there are suppletive affixes as well as suppletive bases. The suffixes /-s, -z, -iz/ forms the plural of most nouns in English, 
but the plural of 'ox' is formed with the suffix /-en/, and the plural of 'child' with /-ren/, (accompanied by internal change of the base). The suffixes /-en and -ren/ are suppletive to the regular suffix /-s, -z, -iz/.

\subsubsection{Zero-Modification}

It is always useful to speak of zero-modification, (zero-suffix, zero-change, etc.), in describing the morphology of a language. As it is known that the overwhelming majority of English nouns form their plural by adding /- s/ suffix to the base, but sometimes a few words form their plural by the addition of a zero suffix symbolized as $/ 0 /$, e.g., deer, sheep, fish, etc.

\section{Derivation}

"The most common word- formation process to be found in the production of new English words. This process is called derivation and it is accompanied by means of a large number of small 'bits' of the English language which are not usually given separate listing in dictionaries. These small 'bits' are generally described as affixes" (Yule, 2006, p. 57).

Affixes are of two types: inflectional or derivational. Inflectional affixes are grammatical in nature and occur after the root, and no further affixation can be added to the form, e.g., 'develops', 'drinks', 'cups'. Inflectional affixes are terminal, and no other suffix can be added after the inflectional suffix is used. Inflectional suffixes do not change the word class.

On the other hand, derivational suffixes, can occur medially, finally or initially, furthermore, derivational affixes make new stems, e.g., 'organize, organizer, organization', 'equipment', 'manly', 'irregular', 'darkness', 'employment'.

Derivational affixes may or may not change the word class, Class-maintaining derivational suffixes are those that produce derived forms of the same class as the underlying form, they do not change the class or parts of speech. Thus, the suffixes/-hood/ and/-ship/ in 'friendship', and 'childhood', are class-maintaining derivational suffixes, they produces nouns out of nouns after affixation. Class-changing derivational suffixes are those that produce form of another class. Thus, the suffixes/-ish/ and /-ment/ in 'boyish' and 'development' have changed the noun into adjective, and the verb into a noun respectively.

\subsection{Ordering among Morphemes}

"The meaning of the word depends not only upon the morphemes that are present but also on the order of their occurrence" (Gleason, H. 1961, p. 57).Thus, the prefixes /re-, un-, dis- , ir-, de-/ in 'reconvene, unhappy, reconstruct, disappear, irregular, device, deceive, receive', are bound morphemes and can only be prefixes to the base, any change in the order of their occurrence, not only be unfamiliar in the sound and appearance, but also actually meaningless to a native speaker. The suffixes /-ness and-ous/ occur finally after the base, and any change in the order of their occurrences will result in changing the meaning. So their order of occurrences is rigidly fixed.

At word level, as it is well known, derivational suffixes can be added after the stem as in 'darkness', 'establishment' or can be followed by other inflectional suffixes as in 'dancers', 'nationals', 'arrangements'. Thus, the order of the occurrence of the morphemes is fixed. On the other hand, inflectional suffixes, which are bound morphemes cannot be followed by any derivational suffix under any condition, e.g., 'goes, singing, cups, backed, marked', etc. That is, they are terminal and no further morphemes can be added.

\section{Inflectional Categories}

English nouns are inflected for the following categories:

1. Number

2. Gender

3. Case, and

4. Person

\subsection{Number}

"The English number system comprises singular, which denotes 'one', and plural, which denotes 'more than one'. The singular category includes common non-count nouns and proper nouns. Count nouns are variable, occurring either singular or plural number 'boy-boys', or have invariable plural 'cattle'" (Quirk \& Greenbaum, 1973, p. 80).

In English, the regular plural is formed by the addition of the sibilant suffix /-s/ to the singular.

It has three allomorphs which are phonologically conditioned, i.e., the choice of /-s, -z, -iz/ is determined by the 
final sound of the nouns to which plural forming suffix appears, e.g., 'books, boys, roses', etc. In other words, the plural morpheme has three allomorphs, i.e., /-s , -z, and -iz/.

In addition to singular and plural, we may distinguish dual number in case of both, either, and neither.

Besides the regular plural morpheme /-s/, there are a number of irregular formations that are as follows:

1. Stem modification, then adding /-s/. e.g., 'thieves, knives, baths'.

2. Adding /-en/ with or without additional internal change in the stem, e.g., 'oxen, brethren, children'.

3. By mutation, a change of vowel in the following seven nouns: 'foot - feet, man - men, woman - women, tooth - teeth, louse - lice, goose - geese, mouse - mice'.

4. By adding a zero morpheme to a few nouns, i.e., the plural is identical to the singular, 'fish, deer, sheep'.

"Foreign plurals often occur along with regular plurals. They are commoner in technical usage, whereas the $-\mathrm{s}$ plural is more natural in everyday language; thus formulas (general) $\sim$ formulae in mathematics), antennas ( general and in electronics) antennae (in biology)" (Quirk \& Grenbaum, 1973, p. 87). For example, 'stimulus stimuli, curriculum - curricula, index - indices, basis - basses, criterion - criteria.

\subsection{Gender}

"English makes very few gender distinctions. Where they are made, the connection between the biological category 'sex' and the grammatical category 'gender' is very close, insofar as natural sex distinctions determine English gender distinction" (Quirk \& Greenbaum, 1973, p. 89).

In English, the gender of nouns as a grammatical device is defined solely in terms of pronouns substitutes -he, she, or it, which may be used in its place. Gender has little role of grammatical significance.

"Gender plays a relatively minor part in the grammar of English by comparison with its role in many other languages. There is no gender concord, and the reference of pronouns 'he, she, and it' is very largely determined by what sometimes referred to as 'natural' gender, for English, this depends upon the classification of persons and objects as male, female or inanimate" (Lyons, John, 1969, pp. 283-84). Thus, a noun that denotes male persons is said to be masculine 'boy, man'; a noun denoting female persons is said to be feminine 'woman, girl'; and a noun denoting thing that is neither male nor female is said to be 'neuter gender' gun, basket'. Another type of gender may be added, that is common gender (or dual gender), child, student, teacher, friend, servant, criminal, novelist, professor, enemy, etc.

\section{Formation of feminine forms:}

The feminine gender of nouns is formed in the following ways:

I. By suppletion, an entirely different base, i.e., 'boy - girl, man - woman, king - queen, lord - lady, uncle - aunt, cook - hen', he goat - she goat, etc.

II. By adding the suffix /-ess/, e.g., 'host - hostess, actor - actress, lion - lioness, waiter - waitress, tiger - tigress, prince - princess, etc.

III. By placing a word before or after, as in, milk man - milk lady, stepson - stepdaughter, grandmother grandfather, stepbrother - stepsister, etc.

IV. By other endings as, 'hero - heroine, administrator - administratrix , executive - executrix , fox - vixen, sultan - sultana.

\subsection{Case}

"There is a great variation in the number and kind of case markings found in different languages. Some languages (e.g., Chinese) do not mark case at all. In English, case marking in the noun is limited to 'a possessive' (or genitive) case, marked in writing by - 's in the regular nouns and by $-\mathrm{s}$ ' in the plural nouns. It links two nouns in a semantic relationship of 'belonging' or 'possession' (e.g., the caw's tail, the girl's name), or in some kind of largely grammatical relationship (e.g., the world's end, the inquiry's conclusions).

In pronouns in English, however, some distinctions are made between subject and object forms, e.g., I - me, she her, they - them (Jackson, H, 1985, p. 15).

English nouns are inflected for the case category known as 'genitive' or 'possessive'. They are marked by an inflectional suffix /-s/, which has three variants /-s, -z, - iz/ as in 'trust's, jug's, judge's respectively.

Thus, the possessive case formation, which are as follows:

1. When the noun is singular, the possessive case is formed by adding/-s/ to the noun, e.g., 'Ahmed's pen', 'the 
king's crown', 'the needle's eye', 'for goodness' sake', 'for Jesus' sake'. (The /-s/ is omitted because of the preceding hissing sounds that occur together).

2. When the noun is plural, and ends in 's, the possessive case is formed by adding only apostrophe', as, 'girls' college', 'students' house', 'passengers' luggage'.

3. When the noun is plural but does not end in 's, the possessive case is formed by adding 's, as in, 'men's club', 'women's house', 'children's book'. There are few irregular formation, as, 'ox- ox's /-iz/, 'fish- fish's /-iz/, 'child children's /-z/, sheep-sheep's /-s/.

\subsection{Person}

"English has three classes of personal pronouns denoting respectively, the person(s) speaking, 'first person', the person(s) spoken to 'second person', other person(s) or thing(s) 'third person'" (Zandvoort, R. W., 1965, p. 128).

The category of person can be clearly defined with reference to the participant roles, The 'first' person is used by the speaker to refer to himself as a subject of discourse, the 'second' person to the hearer, and the 'third' person for persons and things other than the hearer and the speaker.

Personal pronouns are inflected for the following categories: gender (Masc. \& Fem.), number (Singular \& Plural), and case (Nominative, Accusative, and Possessive).

In addition to the personal pronouns, English also has other types of pronouns: demonstrative, Interrogative, relative, reflexive, distributive, and indefinite pronouns. Demonstrative pronouns, in addition to personal pronouns, show some inflection for near and far distance objects, but no gender distinction.

\section{Arabic Noun Morphology}

Arabic morphology structure can be dealt with on bases of form, function or both (د. حسان، 1976). As for the structure of nouns in Arabic, they can be described in the following terms:

\section{Stem-root Structure}

\section{Morphological processes of stem formation.}

\subsection{Stem-Root Structure}

The root system in Arabic gives the basic morphological characteristics of nouns, verbs and particles. The great majority of nouns and verbs have a stem consisting of three consonantal roots, i.e., $\mathrm{C} 1 \mathrm{C} 2 \mathrm{C} 3$. A great number of word patterns can be made by modifying the root by means of affixation, both inflectional and derivational.

For example, from the root /k-t-b/ various words can be derived, such as, /kataba/ 'he wrote', /kita:bun/ 'a book' /maktabun/ 'an office', /ka:tibun/'a writer', etc.

In other words, by modifying the three consonantal roots by means of vowel insertion, a number of words can be derived.

\subsection{Morphological Processes}

The various morphological processes of stem formation are as follows:

\section{Affixation 2. Derivation 3. Inflection}

\subsubsection{Affixation}

The most frequent morphological possess is affixation, which is of three types: prefixes, infixes and suffixes. Affixes are also of two types: inflectional and derivational, preceded or followed by parts of the root. For example, /yadrusu/ 'to study' /darasa/ 'he studied' , /darasat/ 'she studied', /darastu/ 'I studied' , /madrasatun/ 'school', etc.

\subsubsection{Derivation}

The great majority of nouns and verbs are derived from the trilateral root of the third person masculine singular of the perfect of the simple verb. Thus from /qatala/ 'he killed' a host of derivatives exist such as /yaqtulu/ 'to kill', /qita:lun/ 'fighting', /qa:tala/ 'he fought', /qa:tilun/ 'murderer', and so on. The Arabs use the simplest pattern /fa3ala/ 'he did' and use its three radicals /f-3-1/ quite independently of any idea of describing the various patterns of words.

\subsubsection{Derivation of Nouns}

"Word formation in Arabic involves three concepts: (a) the concept of root, (b) the concept of pattern (c) and the concept of form" (Descout, R., 1987, p. 93). The various word patterns are expressed by using the root consisting 
of consonants only.

The actual form of the word is created by inserting vowels within the consonantal root and sometimes by additional consonants which are not part of the root. The actual word formation can be described by using the consonantal pattern /fa3ala/, e.g., /jama3a/ 'he collected', /kataba/ 'he wrote', /la3iba/ 'he played', etc.

Thus, nouns in Arabic are of two classes:

1. Primitive: those nouns that can't be referred to any verbal root, e.g., /farasun/ 'a horse', /qalbun/ 'heart', /kalbun/ 'a dog', /qalamun/ 'a pen', etc.

2. Derived: derived nouns are those nouns that are derived from various verb forms or patterns:

(a) From bi-consonantal root/yd/, the form /yad/ 'hand' is derived. From /bk/ the morpheme /buka:?/ 'weeping' is derived.

(b) From three consonantal root, e.g., /f-?-1/ we have /walad/ 'a boy', /qamar/ 'a moon' , /watan/ 'a homeland', raqam/ 'a number', etc.

In addition to the above mentioned derived nouns, broken plural patterns also fall under derived nouns. This will be dealt with under number with special reference to the pattern and forms of broken plural.

\subsubsection{Derivatives of Nouns}

The most common derivatives of nouns are the following:

(a) The relative adjectives, formed by adding the suffix /iyyun/ to the noun, e.g., /al arabu/ 'Arabs', /arabiyyun/ 'Arabian', /3ilmun/ 'science', /?ilmiyyun/ 'scientific', etc.

(b) Diminutive: which is rarely used, is formed according to the pattern /fu?aylun/, e.g., /kutayyibun/ 'a small book', /bunayyatun/ 'a little girl', etc.

(c) Nouns derived from verbs: nouns derived from verbs of trilaterals, e.g., /qita:lun/ 'fighting', from /qatala/ 'he killed'. /majlesun/ 'council' from /jalasa/ 'sat', etc.

(d) Nouns derived from nouns: some nouns are derived from other nouns, e.g., /insa:niyatun/ 'humanity' from /insa:nun/ 'human', /Isla:miyyun/ 'Islamic' from /Isla:mun/ 'Islam'.

\subsection{Inflectional Categories}

Arabic nouns are inflected for number, gender, case, and person.

\subsubsection{Number}

"Arabic has three numbers categories: singular, dual, and plural. Whereas singular and plural are familiar to most western learners, the dual is less familiar. The dual in Arabic is used whenever the category of 'two' applies, whether it be in nouns, adjectives, pronouns or verbs" (Karin. C, Ryding, 2005, pp. 53-54).

A peculiar feature of the Arabic language is that its nouns, verbs and adjectives have three numbers: singular and plural المثنى ane singular words are unmarked.

\subsubsection{The Dual}

The dual is formed by adding the suffix /-a:ni/ in the nominative, /- ayni/ in the accusative and genitive to the singular of the noun ( feminine and masculine) after the removal of the case ending. For example, /malikun/ 'a king', /malika:ni/ 'two kings' in the nominative case, /malikayni/ 'two kings' in the accusative and genitive cases.

Furthermore, if the singular ends in /a:/, the /a:/ becomes /w/ in the dual, e.g., /?asa:/ 'a stick' becomes /?aswa:ni/ 'two sticks'. If the feminine singular ends in /? $\mathrm{u} /$, the hamza /?/ becomes /w/ in the dual, e.g, /sahra:? $\mathrm{u} /$ 'desert' becomes /sahrawaini/ 'two deserts'.

In addition to word forms, appropriate to the singular and to the plural, which imply more than two entities, Arabic also uses dual when the reference is to two individual entities of category (Beeston, A., 1987, p. 109).

\subsubsection{The Plural}

"There are two kinds of plural in Arabic. Firstly, we have the 'sound plural' الجمع السـالم confined at least in the masculine) to participle and the nouns indicating the profession or habitual actions. Secondly, there is the so called 'broken plural' جمع التكسير which is made according to a pattern by altering the vowel within or outside the framework of the radical consonant" (Cowan, D., 1986, p. 18).

The sound plural is of two kinds: sound masculine plural جمع المؤنث المذكر السالم and the sound feminine plural السـالم. The sound masculine of nouns and adjectives is formed by adding the suffix/-u:na/ for the nominative, 
e.g., /mudarisu:na/ 'male teachers', /mu?alimu:na/ 'teachers' , /najaru:na/ 'carpenters', and /-i:na/ for the other cases after the case ending of the nominative singular has been dropped, e.g., /najari:na/ 'carpenters', /?mu?alimi:na/ 'teachers'.

The sound feminine plural is formed by changing the suffix /-atun/, of the singular into/-a:tun/ for the nominative, e.g., /mudarisa:tun/ 'female teachers', /muslima:tun/ 'muslim women' and /-a:tin/ for the other cases, e.g., /mudarisa:tin/ 'female teachers', /muslima:tin/ 'muslim women'.

Some feminine nouns take a masculine sound plural, e.g., /sanatun/ 'a year', /sinu:na/ 'years' and some masculine nouns take a feminine sound plural e.g., /hayawa:nun/ 'an animal', /hayawana:tun/ 'animals', /naba:tun/ 'plant', /nabata:tun/ 'plants'.

As for the broken plural, it is necessary to know the importance of word forms, or patterns in Arabic. The great majority of Arabic roots are trilateral, consisting of three radical letters, or consonants. The combination of trilateral root gives a basic meaning. By modifying the root, by the addition of suffixes and prefixes, and by the vowel change, a large number of word patterns can be formed from each root. These patterns have got to be learnt along with the singular.

The following are the most frequent and common patterns of broken plural:

i. /af?a:lun/ as in /aqla:mun/ plural of / qalamun/'a pen'.

ii. /fu? u:lun/ as in /mulu:kun/ plural of /malikun/ 'a king'.

iii. /fi? a:lun/ as in /rija:lun/ plural of /rajulun/'a man'.

iv. /fu?ilun/ as in /kutibun/ plural of/kita:bun/ 'a book'.

v. /af? ulun/ as in /a?yunun/ plural of /?aynun/ 'an eye'.

vi. /fu? ala:'u/ as in /aqriba:'u/ plural of /qari:bun/ 'a relative'.

vii. /fu? ala:'u/ as in /sufara:'u/ plural of/safi:run/ 'an ambassador'.

viii. Ifu? la:nun/ as in /bulda:nun/ plural of /baladun/'a country'.

ix. Ifa? a:lilu/ as in /kawakibu/ plural of /kawkabun/'a star'.

x. /mafa:?i:lu/ as in /qana:di:lu/ plural of /qind:lun/ 'a lamp'.

xi. / fa3a;3ilu?/ As in /rasa:'lu/ plural of/risa:latun/ 'a letter'.

In addition to the above mentioned patterns, irregular plurals are also found in Arabic. For example, /'maha:tun/ plural of /'umun/ 'a mother', /miya:hun/ plural of /ma:'un/ 'water', /sufunun/ plural of/safi:natun/ 'ship' etc.

\subsection{Gender}

"Each noun in Arabic is either masculine or feminine as there is no neuter gender" (Shafi, S., 1986, p. 13). Gender is a grammatical category in Arabic. Generally, the feminine gender is formed from the masculine (participle or noun indicating profession) by adding the suffix /-atu/, e.g., /ka:tibun/ 'male writer', /katibatun/ 'female writer', /ibnun/ 'son', /ibnatun/ 'a daughter', etc.

"Arabic exhibits two genders: masculine and feminine. For the most part, gender is overtly marked, but there are words whose gender is covert and shows up only in agreement sequences. The gender category into which a noun falls is semantically arbitrary, except where nouns refer to human beings or other living creatures. Gender is marked on adjectives, pronouns, and verbs, as well, but not inherent, as it is in nouns" (Karin, C. Ryding, 2005, p. 53).

The same feminine ending occurs in many words which have no masculine form, e.g., /madi:natun/ 'a city', /madrasatun/ 'a school', /majzaratun/ 'massacre', /mahkamatun/ 'law court'.

Other feminine endings are / a:, a:'u/ as in , /kibriya:'u/ 'greatness', /kubra:/ 'large or vast', /bushra:/ 'good news'. The adjective agrees with the noun it qualifies, e.g., /al-bana:tu al-kabi:ra:tu/ 'the big or elder girl'.

"Feminine nouns may be ascertained by significance or by their grammatical form. But it is not always easy to recognize gender by significance. Generally, all common and proper nouns that denote females, proper names of countries and towns, names of the body and collective nouns are feminine" (Frayha, Anis, 1958, p. 220). The following classes of words are feminine without requiring a feminine ending:

(a) Nouns denoting a feminine by meaning, e.g., /bintun/ 'a girl', /'ummun/ 'a mother'.

(b) Parts of body which occur in pairs, e.g., /yadun/'a hand', /rijlun/ 'a foot', /?aynun/ 'an eye'. 
(c) Proper names of lands, countries and cities, e.g., /al-Hindu/ 'India', /?ammanu/ 'Amman' , /?ira:qu/ 'Iraq'.

(d) Words that are feminine by usage, e.g., /nafsun/ 'a sole', /su:qun/ 'market', /qamarun/ 'moon', /na:run/ 'fire'.

A number of words are of common gender and may be used as masculine or feminine, e.g., /ibha:mun/ 'a thumb', /siki:nun/ 'a knife', /sama'un/ 'sky'.

The same feminine ending/-atun/ is also used for the singular to form collective nouns, e.g., /ti:nun/ 'fig' plural of /ti:natun/ 'a fig', /?inabun/ 'grapes' plural of /?inabatun/ 'a grape', /zaytu:nun/ 'olives' plural of /zaytu:natun/ 'a single olive'.

\subsection{Case}

Arabic has three cases, and these are simply distinguished by changing the vowel ling of the final consonant (except in the dual and sound masculine plural endings). These cases are as follows:

(a) Nominative رفع

(b) Accusative نصب

(c) Genitive جر

These cases are expressed by the suffixes /-un, - an, -in/, e.g., /sa:riqun, sa:riqan, sa:riqin/ 'a thief'.

The nominative case is used for the subject in a verbal sentence فاعل and that of a nominal sentence مبند/.g. e.g., /wasalat al jara:'du alyawma saba:han/ 'the newspapers arrived this morning'. /alwaladu majru:hun/ 'the boy is wounded'.

It is also used as a predicate of the nominal sentence, e.g., /al- waladu na;'imun/ 'the boy is sleeping'.

The accusative case is used for the subject of the verb, e.g., /darabtu Zaidan/ 'I struck Zaid'. And it is also used for the absolute object المفعول المطلق as in /qaliqtu qalqan/ 'I was upset'.

The genitive case is used for a noun which is connected with another by annexation اضLافة, e.g., /baytu muhammadin/ 'The house of Mohamad'. The relation of a word and its following genitive is called اضطافة and governing word is called مضاف and the genitive مضاف إليه.

"When one noun governs another in the genitive, the first is said to be in the construct state. The governing noun comes first and loses its nunation" (Tritton A. S., 1970, p. 33).

Thus, the word that governs the genitive is itself definite but never takes the article, e.g., /baytu rajulin/ 'The house of a man', /baytu -rrajuli/ 'The house of the man'.

All prepositions govern the genitive, e.g., /fi:/ 'in' as in, /fi: busta:nin/ 'in a garden', /li/ 'to or for' , as in ,/li waladi/ 'for the boy', /min/ 'from', as in, /min al buyu:ti/ 'from the houses'.

5.6 Person

Personal pronouns are of two types, which are as follows:

(1) Independent (free or unattached) ضمير منفصل

(2) Dependent (bound) ضمير منصل, i.e., suffixed to nouns , verbs or prepositions.

The independent personal pronouns are used in the nominative case. They are as follows:

Singular: /'ana:/ 'I' (masculine and feminine), e.g., /'ana: rajulun/ 'Iam a man', /'anta/ 'You' (masculine), e.g., /'anta waladun/ 'You are a boy', /'anti / 'You' (feminine), e.g., /'anti bintun/ 'You are a girl', /huwa/ 'He' , e.g., /huwa rajulun/ 'He is a man', /hiya/ 'She', e.g., /hiya bintun/ 'She is a girl'.

Dual: /'antum:' You two' (feminine and masculine), e.g., /'antuma: binta:ni/ 'Youe two girls', /huma:/ , e.g., /huma; rajula:ni/ 'They two are men'.

Plural: /nahnu/ 'We' (masculine and feminine), e.g., /nahnu awla:dun/ 'We are boys' , /nahnu bana:tun/, 'We are girls'.

I'antum / 'You' (masculine), e.g., /'antum rija:lun/ 'You are men', /'antunna/ 'You' (feminine), e.g., /'antunna nisa:'un/ 'You are women', /hum/ 'They' (masculine), e.g., /hum awla:dun/ 'They are boys', /hunna/ 'they' (feminine), / hunna bana:tun/ 'They are girls'.

The dependent (or attached) pronouns, on the other hand, are bound morphemes. They are mainly suffixes occur in the oblique case /-i, -ni, -ka,-ki,-hu,-ha/ (for singular), /kuma:, huma, hima/ (for dual) and Ina:, kum, hum, hunna/ (for plural). Such suffixes can be attached to nouns, verbs, and prepositions as follows: 
(a) Suffixed to verbs as direct object, e.g., /qra'ahu/ 'He read it'.

(b) Suffixed to nouns to indicate possession, e.g., /qalami:/ 'My pen', /baytukuma:/ 'Your house' ( dual masculine and feminine), /kita:buhu/ 'his book' , /kita:buhuma:/ 'Their book'.

(c) Suffixed to prepositions, e.g., /lukum/ 'Yours, for you', /minhu/ 'from him', /minha:/ 'from her', /lana:/ 'for us, or ours', etc.

In addition to personal pronouns, Arabic has demonstrative, relative, and interrogative pronouns.

\section{Findings and Conclusion}

The contrastive analysis of the noun morphology in English and Arabic, carried out in this research, reveals the following facts:

(1) Both English and Arabic share some features in their derivational structure. Both suffixes may be added to form nouns, verbs and adjectives.

(2) In Arabic, the root system represents the basic morphological characteristics in the structure of nouns and verbs. Every word in Arabic may be referred to a significant root consisting of three consonants.

By means of morphological processes of adding suffixes, internal vowel modification, infinite number of nouns and verbs can be derived.

(3) The derivational suffixes in both languages determine the distribution and function of words within the sentence.

(4) Both English and Arabic almost use the same morphological processes.

(5) In Arabic, several nouns and verbs are derived with the help of affixes and vowel modifications within the root.

(6) Arabic derivational system, in comparison to English, is very complex which may cause a few difficulties for the second language learners.

(7) Both English and Arabic have the same number of word classes.

(8) Both English and Arabic nouns are inflected for the categories of number, gender, case, and person).

(9) English nouns have two numbers: singular and plural. Whereas, Arabic nouns have three numbers: singular, dual and plural. The plural is also of two kinds: sound plural (masculine \& feminine) and broken plural.

(10) English has three genders: masculine, feminine, and neuter. Gender is solely confined to personal pronouns. Whereas Arabic has only two genders: masculine and feminine.

(11) English nouns are inflected for genitive case. Whereas, in Arabic, nouns are inflected for three cases, namely, nominative, accusative, and genitive. These cases are distinguished by changing the vowel ling of the final consonant.

(12) Personal pronouns in English system are not as complicated as in Arabic. It is rather simple with regard to number, gender and case distinction. In Arabic, there is a full set of distinction for number, gender, and case.

(13) Arabic has two types of personal pronouns, namely: dependent and independent. Arabic has twelve forms of independent pronouns, distinguished in number as: singular, dual, and plural. Whereas, English has eight personal pronouns distinguished in number as: singular and plural.

(14) There is no gender distinction between $2^{\text {nd }}$ person singular and plural, whereas, Arabic gender distinction is made.

(15) Both English and Arabic have one form of the $1^{\text {st }}$ person singular and plural.

(16) English does not make any gender distinction of demonstrative pronouns. It does distinguish between near and far objects in number. Arabic makes distinction of gender as well as of number.

Thus, it has been observed that both languages share some common features as well as several differences. In the light of such findings, the linguistic problems of the Arabic speakers learning English may be solved. In other words, through this comparison and contrast, the teacher will be aware of the structure of the two languages and the areas of difficulties of the learners at the morphological level. It is also hoped that the analysis and results of this study would be useful both to teachers and textbooks writers of English and Arabic as foreign languages. 


\section{References}

\section{English Sources}

Beeston, A. F. L. (1987). Written Arabic: An Approach to the Basic Structure. Cambridge University, London.

Block, B., \& Tagger, G. (1972). Outlines of Linguistic Analysis. Linguistic Society of America.

Cowan, D. (1986). An Introduction to Modern Literary Arabic. London: Cambridge University Press.

Descout, R. (1986). Applied Arabic Linguistics and Signals \& Information Processing. New York.

Frayha, A. (1958). The Essentials for Arabic: A Manual for Teaching Classical and Colloquial Arabic (2nd ed.). Beirut: Khayat.

Fries, C. (1957). Teaching and Learning English as a Second Language. New York.

Gleason, H. A. (1961). An introduction to Descriptive Linguistics. New York: Holt, Richard \& Winston.

Hocket, C. (1970). A Course in Modern Linguistics. New York: MacMillan.

Hywood, J. A., \& Nahmad, H. M. (1965). A New Arabic Grammar of the Written Language. London: Lund Hemphric.

Jackson, H. (1985). Discovering Grammar. Pergmen Institute of English. Oxford: Pergman Press.

Karin.C. R. (2005). A reference Grammar of Modern Standard Arabic. Cambridge: Cambridge University Press.

Lado, R. (1957). Linguistics Across Culture; Applied Linguistics for Language Teaching. Ann Arbor: University of Michigan Press.

Liebert, B. (1971). Linguistics and the New Language Teacher. New York: MacMillan.

Lyons, J. (1969). An introduction to Theoretical Linguistics. Cambridge: Cambridge University press.

Nickel, G. E. D. (1971). Papers in Contrastive Linguistics. Cambridge: Cambridge University press.

Quirk, R., \& Greenbaum, S. (1990). A University Grammar of English. England: Longman.

Shafi, S. (1978). A Course in Spoken Arabic. Bombay: Oxford Press.

Tritton, A. S. D. Litt. (1970). Teach Yourself Arabic. London: English Universities Press.

Wardhaugh, R. (1970). The contrastive analysis hypothesis. TESOL Quarterly, 4. TESOL Convention March 1970. http://dx.doi.org/10.2307/3586182

Yule, G. (2006). The Study of Language. Cambridge: Cambridge University Press.

Yushmanove, N. V. (1961). The Structure of the Arabic Language. Center for Applied Linguistics of Modern Languages Association of America, Washington.

Zandvoort, R. W. (1965). A Handbook of English Grammar. England: Longman.

Arabic Sources

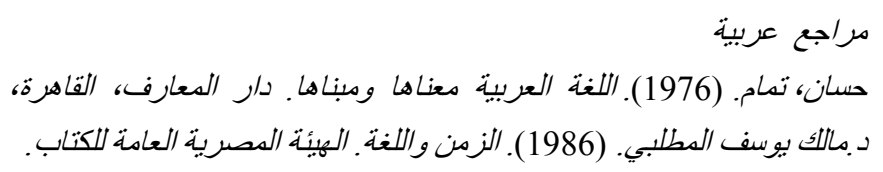

